\title{
ISSUES AND CHALLENGES OF GEOGRAPHICAL INDICATION IN INDIA
}

\author{
Kumari Youkta \\ Research Scholar, \\ Department of Humanities and Social Sciences, \\ Indian Institute of Technology Patna, \\ Bihar, India,
}

\author{
Shreya Nupur \\ Research Scholar, \\ Department of Humanities and Social Sciences, \\ Indian Institute of Technology Patna, \\ Bihar, India
}

Article DOI: $\underline{\text { https://doi.org/10.36713/epra5323 }}$

\begin{abstract}
In the recent years Geographical Indications have grabbed attention as an important property right issue in a country like India where there is great diversity on cultural and geographical grounds which if utilized wisely can benefit the country a lot. But several challenges and issues are there due to which some states in India are lagging behind when some are really performing well. The objective of this study is to dig out the reasons behind this disparity among states on the grounds of GI registration. For this the study takes help of secondary sources like WIPO, WTO, Manupatra.com, IPI, case studies from literatures, journals, books etc. and explains it by making use of bar graphs and pie charts. The findings of this study will carry significant implications for Central as well as State Government of India in terms of addressing this challenge and developing strategies so that potential benefits ingrained in Geographical Indications can be realized efficiently.
\end{abstract}

KEYWORDS: Geographical Indications, WTO, TRIPS agreement, Challenges, Tag

\section{INTRODUCTION}

The term 'Geographical Indications' (GIs) managed to get place in the dictionary of international intellectual property (IP) law through its inclusion in the Trade-Related Aspects of Intellectual Property Rights (TRIPS) agreement of the World Trade Organization (WTO).

TRIPS has defined GI as an indication which recognizes a good according to their originating area in the territory of a member, where that good must possess the attributes, quality and other characteristics of that geographical location (Article 22 of TRIPS). In other words, Geographical Indication (GI) can be defined as one of the important property right out of six Trade-Related Intellectual Property Rights (TRIPS) of the World Trade Organization (WTO), this can be recognizing as a good that originates from a specific region and contains the characteristics and specialty of that particular region. GI has got favorable attentions from developing countries because its future socioeconomic benefits led many to believe that GI would emerge as new revolution in IPRs as consider it as sleeping beauty IPR (WIPO, 2017).

In Indian context Geographical Indication of Goods Act 1999 came into existence from 15 th September 2003 with the aim to provide legal recognition and protection to the goods comes under GI products. This act was enacted due to India's obligations in TRIPS under WTO. There are three main objectives that comes under GI protection Act, 2003:

1) Protection and prosperity of producers of GI goods, so that they would encouraged to produce it.

2) Protection of consumer from misleading GI product.

3) Promotion of GI goods international export market. 


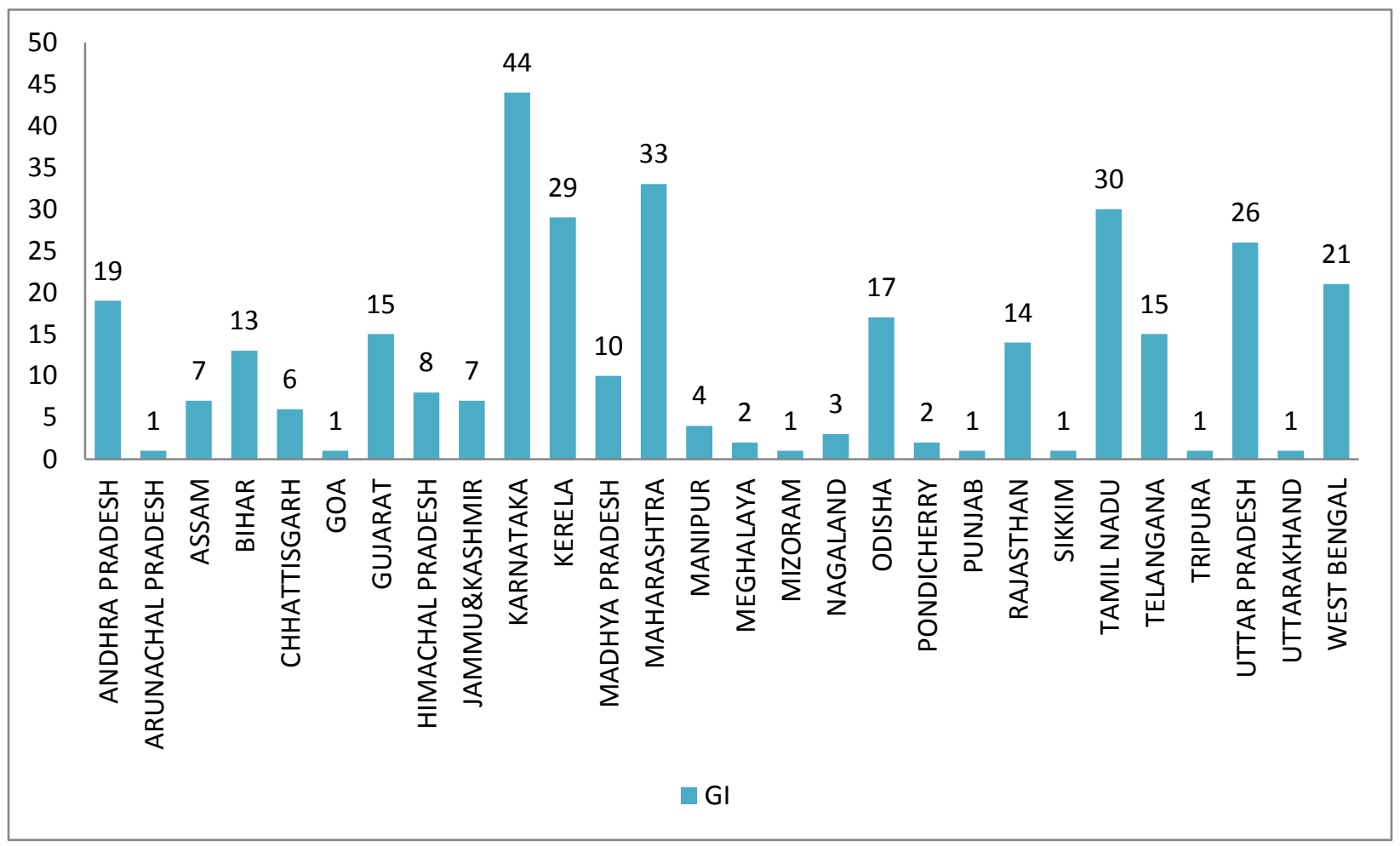

Source: GI Registration office

India at present have total 344 products registered as GI products in which 13 are international GIs and rest are domestic GIs. India is having a very rich culture and diversity which if utilized effectively can benefit the whole economy a lot. But still many states in India are lagging behind in rearing the benefits of GI. One can find a great disparity among states in India regarding GI Registration. Karnataka, Maharashtra, Tamil Nadu, Kerala are some states performing so well while on the other hand states like Arunachal Pradesh, Punjab, Mizoram, Sikkim, Tripura and Goa having only one GI and it is very strange that Jharkhand is having no any GI products registered yet. The whole picture of state's performance is shown above with the help of Bar Graph.

This situation poses a question why this disparity is there? and What are the issues and challenges behind these gaps? which this study has tried to answer.

\section{LITERATURE REVIEW}

Abundance of literature are available which talks about different aspects of GI in the context of India as well as world. In a study by Das (2010) he has highlighted that India has large number of product in its coffer that can qualify as GI product there in need of awareness about this act because this concept is new to India. There is need to come forward different stakeholders for strategic intervention so that India could succeed in GI initiatives. Since most of the GI in India is related to traditional knowledge it has opportunity to enlarge its scope through building brands. In addition to that it has potential to develop the traditional hotspot such as "Cultural tourism" which will give impetus to rural India in terms of tourism and employment.

Agdomar (2008) emphasized in his paper that if GI gets protected this will serve several purposes like it will protect the community and source of that product, in addition to that it will help in increasing quality and standard, which in turn will help in generating employment. Rangnekar (2002) focused on legal aspect of GI protection and implementation of law at international as well as domestic level. This subject has been dealt in detail by Gopalkrishnan et al. (2007) who examined the nature and tools adopted for the protection of GIs and traditional knowledge in India and other south Asian countries. They examine the usefulness and effectiveness of GI laws on socioeconomic conditions in these countries. We know that 
India is an agriculture based economy, this economy can be developed by commercialization and promotion of agro based products through GI mechanism. This can emerge as alternate channel of agricultural sector development (Rehmah, 2017). GI products can generate alternate spillover effect on tourism industry, which in turn can generate employment and income generation (Vats, 2016).

Another study by Gulati (2016) have emphasized that GI can be seen as an asset for the poor people who are associated with production of GI product and associated with traditional knowledge. She also highlighted the importance of GI tag to maintain the originality and feature of the product and advocated for spreading awareness about the product and GI tags to avoid piracy and misleading information about the product.

There are several studies dealing with the issues of GIs but very few literature is focusing on the issues and challenges that GI producers and consumers facing. This paper is highlighting the issues and challenges of GI products and fills the important gap in this field of literature.

\section{OBJECTIVE}

To dig out the reasons for why some states are ahead while some are lagging behind in registering for GI products in India by using bar graphs and pie charts.

\section{METHODOLOGY}

Data sources: This study has used secondary data available on GI Registry office of India, WTO, WIPO etc. Support of case studies have also been taken from journals, newspapers, books etc.

Tools: All the information have been shown by using Pie charts and bar graphs.

\section{KEY FINDINGS}

This study suggests that there are several loop holes on legal, social, economic, geographical and technical grounds that are really a very big challenge to chase before some states in India regarding GI Registration.

\section{1) Legal Challenges}

$>$ GI Registration Act in India: The Geographical Indications of Goods (Registration and Protection) Act, 1999 (Act 48 of 1999) came into force in India with effect from15 September 2003. This Act promises to provide

- Adequate protection to the producers of GI goods.

- Protection to consumers from deception, and

- Promotion of goods bearing GI in export market.

But in reality there are several inadequacies in this act which is needed to be addressed as discussed below:

- No effective enforcement mechanism are there at domestic as well as at export markets.

- There is no any agency available to monitor post-GI mechanism in India.

- It does not lay much emphasis on inspection and monitoring mechanism for GI protection, due to which competitors try to free ride over its reputation. However, this leads to loss of trust on the brand, they mislead consumers, in all that process the one who loose most is actual right holder.

$>$ Geographical Indication Registration process in India:

From the above drawn flow chart of GI Registration process in India one can easily analyze the lengthiness of it due to the time lag involved in the process of registration-from application, scrutiny, acceptance, advertisement in Journal, opposition if any, to final registration. Lots of GI registration cases are pending in India which is very discouraging for any producer who is willing to register for any GI products. 
Table 1: GI Registration Process

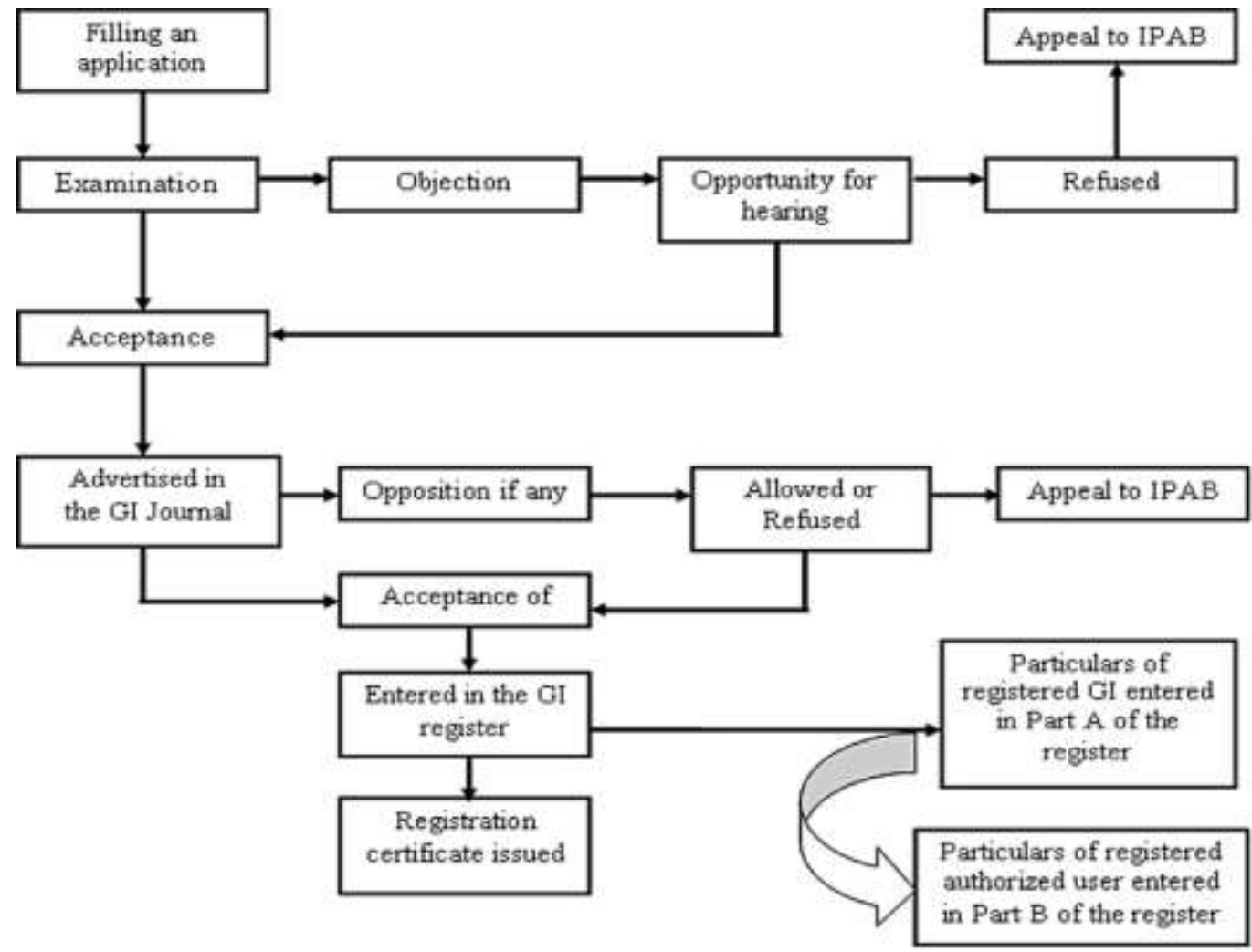

Source: Geographical Indication Registry office

The GI status of India is shown below with the help of the pie chart

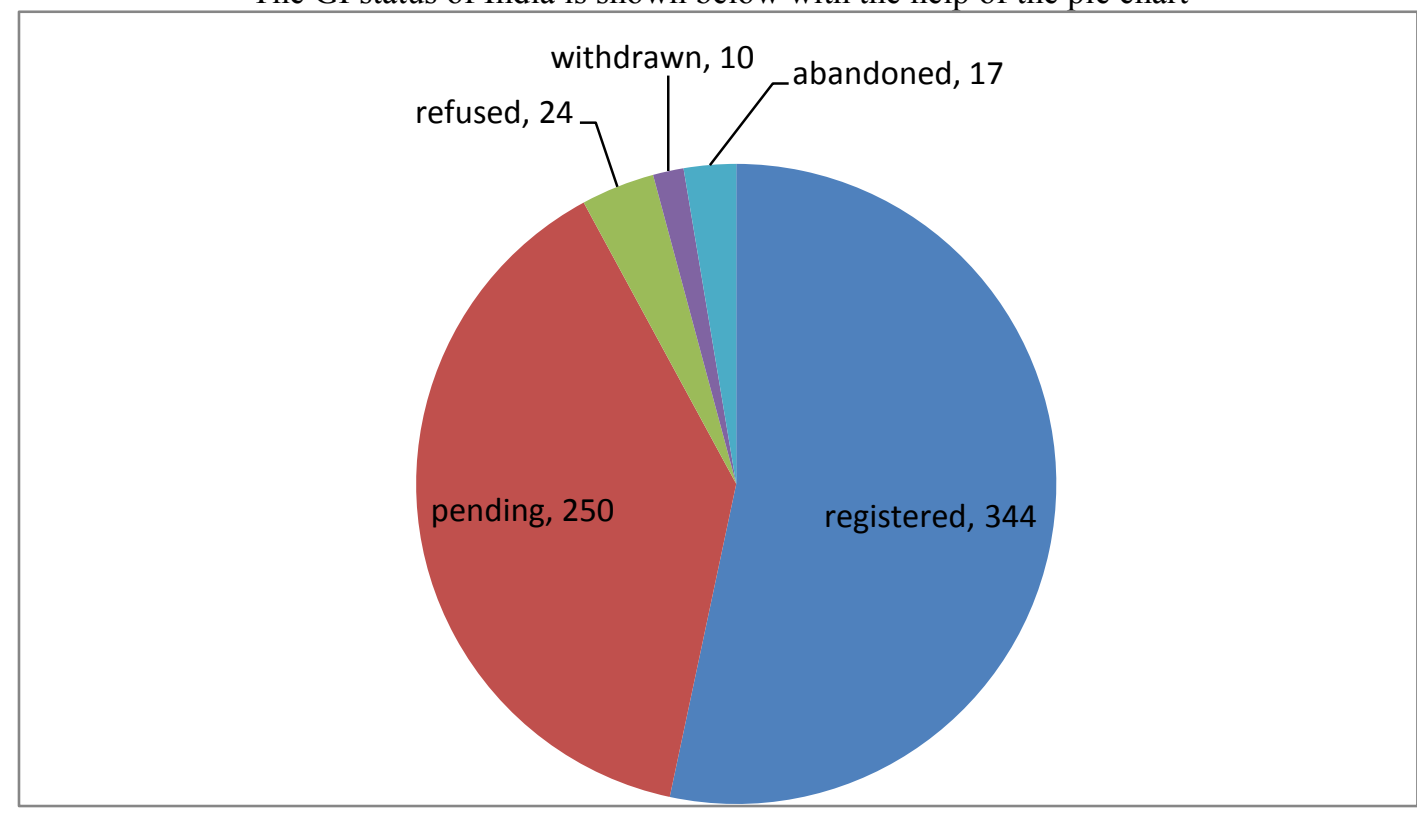

Source: GI Registry office 


\section{2) Economic Challenges}

$>$ Marketing costs: In order to exploit the economic opportunities arises by GI products, to a greater extent, government should use effective marketing techniques and promotional activities. It can require a lot of efforts in terms of time, patience, money, quality control and very effective planned marketing strategy so that a GI product can turn into an international GI brand and it becomes a tedious task for rural producers in India who have a very less knowledge about it.

> Monitoring cost : In the era of science and technology, infringement has become a very common problem not only for producers but also for consumers. In order to monitor it a very sound post GI mechanism is required but it leads to heavy cost burden which is out of the capacity of most of the producers especially rural producers in India.

One important example to understand the complexity of monitoring task is case of Darjeeling Tea, around 9.4 million is spent by Tea Board of India in legal battle and hiring of international watch agency so that they could fight against infringement.

\section{3) Social Challenges}

Lack of awareness: Although GI Act 1999 came into force in 2003 in India but still lots of people in India are not aware of it. How to file an application? where to file? how to monitor infringement activities if going on? etc. are puzzling for producers especially in rural areas. It is due to lack of awareness that individual's proprietorship in total GI registration is very less and Government of India is having the highest percentage proprietorship

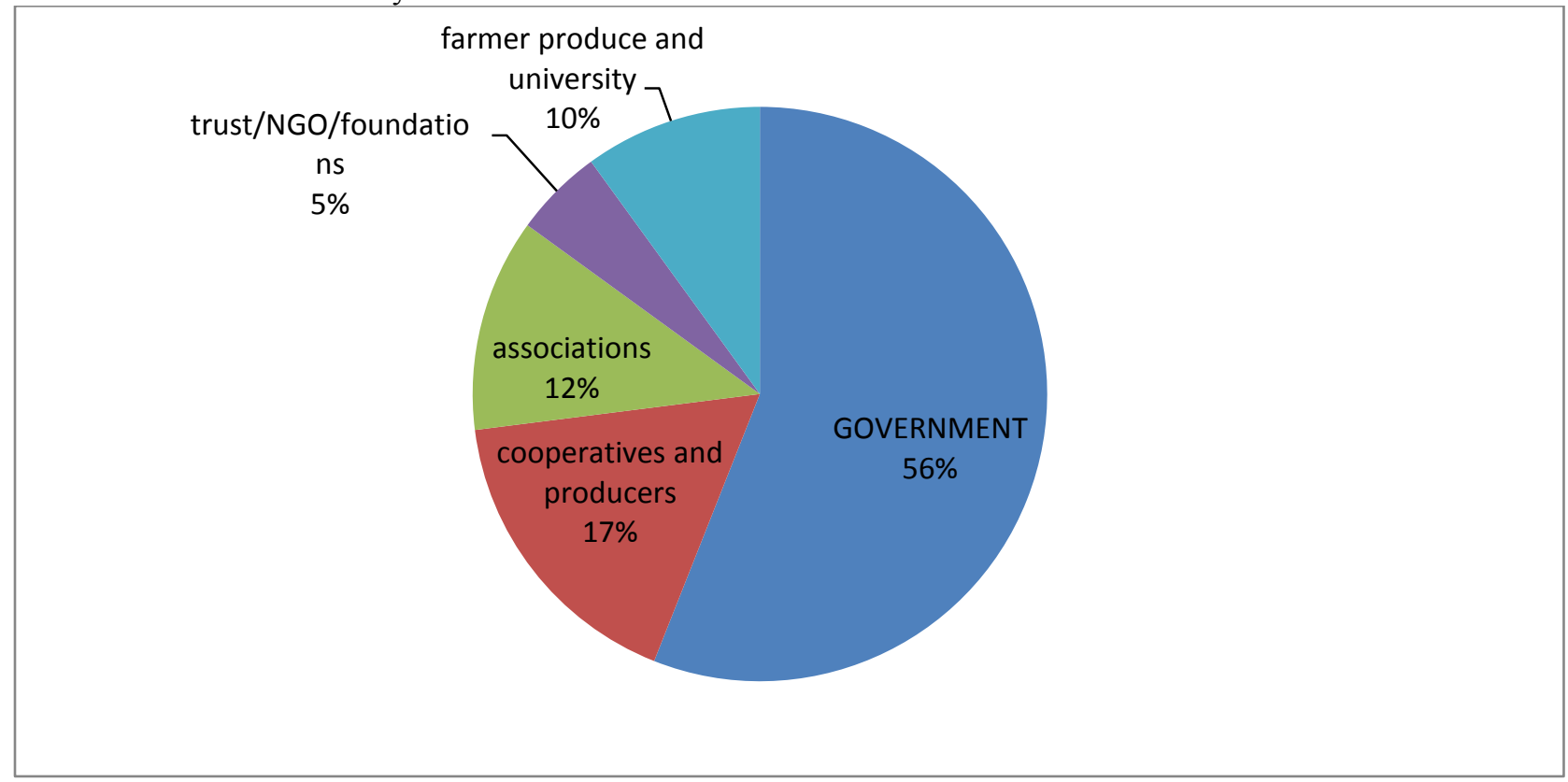

Source: compiled from GI journal and GI Registry

i.e. $56 \%$ which is more than half of the total GI registration in India. The pie chart given above shows the percentage proprietorship of different entities in total GI Registration in India.

\section{4) Geographical Challenges}

$>$ Ambiguity of exact location : A lot of ambiguities arises related with the specific location to be considered as the origin place for the specific product and it creates a lot of problems. As in India tussle is going on for Basmati rice . Punjab , Haryana, Himachal Pradesh, UP, J\&K, and Delhi region have been considered as the Basmati rice growing regions but now Madhya Pradesh and Pakistan are also claiming for it.

$>$ Distance from GI office : In India there is only one GI Registry office, that is in Chennai so it is very inconvenient for producers of other states which are far apart from Chennai to approach the registry office.

5) Technical Challenges

$>$ Infringement techniques: In the era of advancement of technology lots of sophisticated tools have been developed which 
can copy an item in such a way that it is impossible to differentiate between the original one and the duplicate one. This is not only a threat for the authorized producers of that product but also for the consumers because on the one hand where the authorized producer gets deprived from the benefits of producing the product while on the other hand consumers also gets cheated.

\section{CONCLUSION AND SUGGESTIONS}

Undoubtedly a great disparity is there between states in India regarding GI registration. On the one hand there are some states like Karnataka, Kerala, Maharashtra and Tamil Nadu who are performing so well while on the other hand there are states like Jharkhand, having no GI, and Arunachal Pradesh, Goa, Mizoram, Punjab, Sikkim, Tripura having only one GI . So major steps are required to be taken in order to correct it so that potential of GI can be utilized effectively for fastening the pace of growth and development of the country and Government can play an important role in it.

- Although several efforts have been put by the State Government to grab this opportunity through merging of GI products marketing with the department of tourism. But these initiatives are limited only to areas with informed and aware civil societies, which requires further expansion.

- Government should try to make strong linkage process for promotion, branding and distribution of the product, and also should try to make its reach to foreign countries which is very much required.

- Provision of Strong punishment should be there for infringers in GI Regulation.

- $\quad$ Strengthening post GI mechanism so as to monitor infringement activities not only inside the country but also across the world.

- Awareness campaigns especially in rural areas.

\section{REFERENCES}

1. Agdomar, $M$ (2008) Removing the Greek from Feta and Adding Corbel to Champagne: The Paradox of Geographical Indications in International Law, retrieved from www.lexisnexis.com

2. Das, K. (2010). Prospects and challenges of geographical indications in India. The Journal of World Intellectual Property, 13(2), 148-201.
3. Gopalakrishnan.N, Prabha S, Babu, A (2007) Exploring the relationship between geographical indication and traditional knowledge: retrieved from www.ipsorline.org/ictsd/docs/gopaletal\%20Gi $\underline{\& t k . p d f}$

4. Gulati S. (2016). Geographical Indications in India and the case of famous Indian weave: Banarasi Brocade. International Journal of Research Granthaalayah, 4(12), 137-146.

5. Rangnekar.D. (2002) the pros and cons of stronger geographical indication protection, bridges between trade and sustainable development, retrieved from http://www.ictsd.org/monthly/bridges/BRIDGE S\%206-3.pdf

6. Rahmah, M. (2017). The protection of agricultural products under geographical indication: An alternative tool for agricultural development in Indonesia. Manupatra Intellectual Property Report.

7. Vats, N. K. (2016). Geographical indicationthe factors of rural development and strengthening economy. Journal of Intellectual Property Rights, (21), 347-354. 